\title{
ESTILOS FLUVIAIS E EVIDÊNCIAS DE MUDANÇAS AMBIENTAIS NA PLANÍCIE DO RIO MIRANDA, PANTANAL
}

\section{FLUVIAL STYLES AND ENVIRONMENTAL CHANGES IN THE MIRANDA RIVER PLAIN, BRAZILIAN PANTANAL}

\author{
Eder Renato Merino \\ Universidade Estadual Paulista (UNESP), Programa de Pós-Graduação em Geociências e Meio Ambiente, \\ Avenida 24 A, 1515 - Bela Vista, Rio Claro/SP - CEP 13506-900 \\ E-mail:ermerino82@yahoo.com.br \\ Mario Luis Assine \\ Universidade Estadual Paulista (UNESP), Professor do Departamento de Geologia Aplicada e Programa de \\ Pós-Graduação em Geociências e Meio Ambiente, Avenida 24 A, 1515 - Bela Vista, Rio Claro/SP - CEP 13506-900 \\ E-mail: assine@rc.unesp.br \\ Fabiano do Nascimento Pupim \\ Universidade Estadual Paulista (UNESP), Programa de Pós-Graduação em Geociências e Meio Ambiente, \\ Avenida 24 A, 1515 - Bela Vista, Rio Claro/SP - CEP 13506-900 \\ E-mail:fabianopupim@yahoo.com.br
}

\section{Informações sobre o Artigo}

Data de Recebimento: $08 / 01 / 2012$

Data de Aprovação: $13 / 08 / 2013$

\section{Palavras-chave:}

Rio Miranda; Pantanal; rio meandrante.

\section{Keywords:}

Miranda river; Pantanal; meander river.

\section{Resumo}

O rio Miranda é um importante afluente do rio Paraguai e tem grande parte de seu curso na planície do Pantanal. A sinuosidade varia de média a alta, sendo do tipo meandrante na maior parte do seu percurso em domínio aluvial. Com base nos padrões do canal e da planície, três segmentos fluviais com diferentes estilos foram caracterizados e descritos. Ainda nos domínios do planalto, forma um cinturão de meandros numa planície agradacional, que está confinada em vale no embasamento cristalino. O rio deixa de correr num cinturão de meandros ao adentrar no Pantanal, para formar um cordão composto por canal e diques marginais que se destaca pela elevação mais alta em relação à planície agradacional, que se torna mais larga ao deixar o vale confinado. Paleocinturões de meandros e grandes meandros abandonados com dimensões superiores às dos canais atuais, existentes nas planícies agradacionais, permitem interpretar importantes mudanças ambientais e paleohidrológicas ocorridas a partir do Pleistoceno tardio. No seu baixo curso, volta a correr num cinturão de meandros, agora inciso em depósitos aluviais mais antigos, o que denuncia a natureza degradacional da planície distal do rio. Esta planície é palco da ação erosiva de fluxos de águas em lençol durante as inundações e de incisão por rede de pequenos canais tributários que drenam a planície depois das cheias. A avulsão ocorrida nas proximidades do Morro do Azeite desempenhou importante papel na configuração do traçado do canal atual do rio Miranda, deslocando em $20 \mathrm{~km}$ para norte sua foz no rio Paraguai. 


\begin{abstract}
The Miranda river is an important tributary of the Paraguay river and most of its course is in the Pantanal wetland. The river is mostly meandering in the alluvial domain. Based on the channel patterns and fluvial plain morphology, three fluvial segments with different styles is here characterized and described. In the plateau domain, the river meanders in an agradacional plain, confined in a valley sculptured in the crystalline basement rocks. The agradational plain unconfines at the entrance into the Pantanal wetland and the river changes its style and becames an alluvial ridge composed by channel and marginal levees with elevation higher than the floodplain. Paleomeander belts and abandoned bends, with dimensions larger than the current channels, present in the aggradational plains, allow us to interpret that important environmental and paleohydrologic changes have been occurred since the late Pleistocene. In the lower course the river returns to flow in a confined meander belt, but incised in older alluvial deposits, which denounces the degradational nature of the distal fluvial plain. This plain has been affected by the erosive action of sheet flows during floods and incision by small tributaries channels which drain the plain after floods. The avulsion that took place near the Morro do Azeite played an important role in the configuration of the current Miranda river course, changing $20 \mathrm{~km}$ north its confluence with the Paraguay River.
\end{abstract}

\section{Introdução}

O Pantanal possui extensão territorial de aproximadamente $138.000 \mathrm{~km}^{2}$ e é considerado a maior área alagável (wetland) do planeta (JUNK et al., 2006). Devido à grande biodiversidade e a características naturais peculiares, foi tombado pela UNESCO como Reserva da Biosfera e Patrimônio Natural da Humanidade no ano de 2000 (Figura 1).

A planície do Pantanal é circundada pelos planaltos de Maracaju-Campo Grande e Taquari-Itiquira a leste, Guimarães e Parecis ao norte, Urucum-Amolar a oeste e Bodoquena ao sul (ASSINE e SOARES, 2004). É uma ampla planície aluvial com baixo gradiente topográfico e altitudes que variam de 60 a $180 \mathrm{~m}$ acima do nível do mar. Tais características fazem com que o escoamento superficial seja bastante lento e, em decorrência, ocorra longo tempo de permanência de água no sistema.

Considerável área da planície pantaneira permanece alagada durante alguns meses do ano (normalmente de dezembro a maio). Rios com diferentes bacias de drenagem nos planaltos e áreas com diferentes pulsos de inundação, ou ondas de cheia (JUNK et al., 1989), fazem com que diferentes áreas apresentem cheias com picos de inundação defasados, o que tem servido de base para a proposição de diferentes "pantanais" (HAMILTON et al., 1996; SILVA e ABDON, 1998; PADOVANI, 2010). Segundo Padovani (2010), o nível de inundação é questão estratégica para a utilização do Pantanal, e as variações sazonais das condições hidrológicas formam planícies distintas (os diferentes “pantanais") quanto à duração e altura das inundações.

Para Assine e Soares (2004), os diferentes pantanais são expressão de diversos sistemas deposicionais, sendo a planície fluvial do Rio Paraguai coletora das águas de vários megaleques fluviais formados por rios que têm suas nascentes nos planaltos circundantes. Muitas das feições morfológicas destes sistemas são reliquiares, testemunhando evolução paleogeográfica condicionada por mudanças climáticas, alterações do nível de base regional e variação da descarga fluvial que vêm ocorrendo desde o Pleistoceno Tardio (TRICART, 1982; AB'SABER, 1988; SOARES et al., 2003; ASSINE e SOARES, 2004; ASSINE, 2005; KUERTEN e ASSINE, 2011).

Estudos sobre sistemas fluviais têm recebido grande atenção em todo mundo nos últimos anos (STOTT, 2011). Trabalhos sobre os sistemas fluviais dos rios Paraguai (ASSINE e SILVA, 2009; KUERTEN e ASSINE, 2011), Taquari (ASSINE, 2005; ZANI et al., 2012) e São Lourenço (CORRADINI e ASSINE, 2012) têm contribuído para a compreensão da dinâmica e evolução geomorfológica desta singular planície encravada na Depressão do Alto Paraguai, no Centro-Oeste do Brasil.

Muitos rios do Pantanal, especialmente os de sua borda sul, ainda carecem de estudos focados na sua geomorfologia fluvial. Dentre eles merece destaque o rio Miranda, que tem nascentes no Planalto de Maracajú-Campo Grande, extensão de aproximadamente $765 \mathrm{~km}$ e bacia hidrográfica com área de aproximadamente $44.000 \mathrm{~km}^{2}$ no Estado de Mato Grosso do Sul. Os tributários de sua margem esquerda (Salobra, Prata, Formoso, dentre outros) drenam rochas carbonáticas da Serra da Bodoquena. Já os tributários da margem direita (Nioaque, Aquidauana, Santo Antônio, dentre outros) drenam áreas do planalto de Maracajú-Campo Grande, onde predominam basaltos e arenitos da bacia do Paraná.

Este estudo tem como objetivo apresentar a compartimentação geomorfológica do trecho aluvial do rio Miranda (Figura 1), bem como discutir as mudanças de estilo do canal e sua interação com outros rios que compõem a porção sul do Pantanal. 


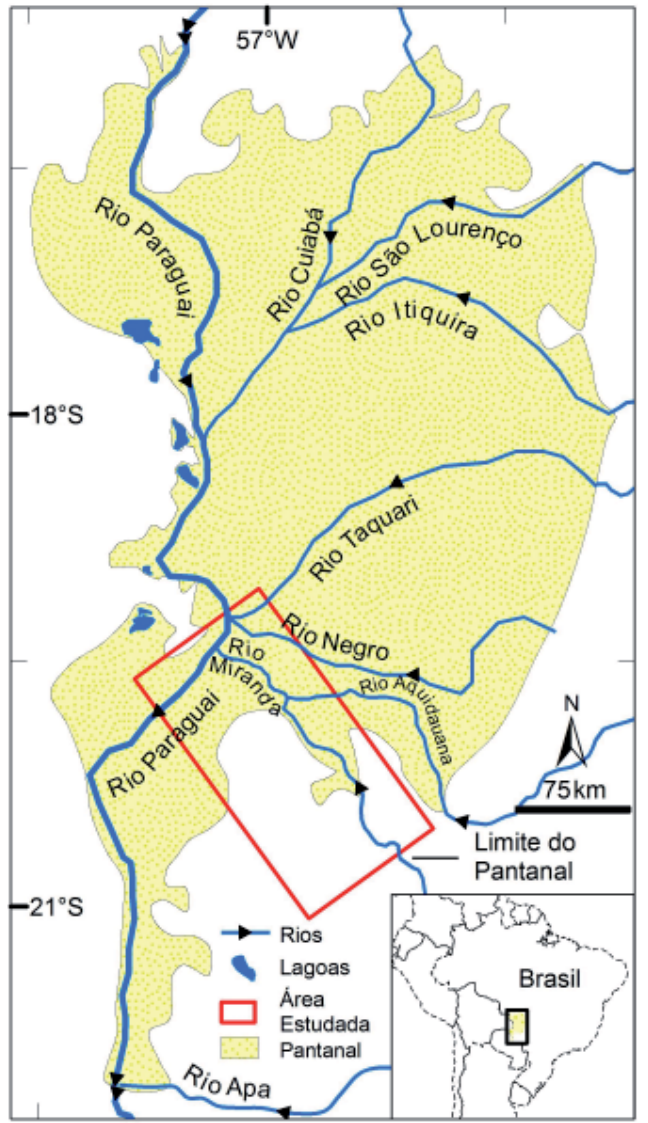

Figura 1 - Localização da área estudada.

\section{Métodos e meios}

Para caracterização geomorfológica do rio Miranda em seu trecho aluvial foi construído um banco de dados geográficos no software ArcGis 9.3.1, com o sistema de referência espacial e georreferenciamento de dados no datum WGS84 zona $21 \mathrm{~S}$.

Processamento digital de imagens Landsat 7 ETM+, ASTER e mosaicos TM Landsat 'Geocover' foram realizados no software ENVI 4.6. Composição colorida "RGB" bandas R7G4B2 do sensor Landsat e bandas R3G2B1 do ASTER, bem como "Análise das Principais Componentes Seletivas" (APCS), foram os principais processamentos utilizados. As imagens RGB foram utilizadas para delimitar a planície aluvial e as imagens derivadas das APCS para diminuir a generalização dos alvos espectrais e realçar formas de relevo. Imagens de alta resolução espacial foram obtidas do plug in Bing Maps Aerial, que possui interface direta com o software ArcGis 10, e também do Google Earth.

Modelos digitais de elevação, elaborados no software Global Mapper 11, a partir das informações altimétricas do componente SAR banda-C do SRTM/NASA, permitiram melhor definição do limite da planície pantaneira com o embasamento cristalino e realçaram diferentes feições do terreno, tais como formas deposicionais compostas por canais e diques marginais.

A vetorização dos contatos geomorfológicos foi realizada no software ArcGis 10. Duas campanhas de campo e um sobrevoo da área foram realizados para validação das informações obtidas com base na interpretação dos dados orbitais. Em uma das campanhas foram coletadas informações específicas sobre a vazão do rio Miranda com a utilização de "acoustic doppler current profiler" (ADCP). Dados sobre a vazão do rio para o período de 2002-2011 (Estação Estrada MT-738, código 66900000) foram obtidos junto à Agência Nacional de Águas (ANA).

Para a compartimentação geomorfológica foram realizadas diversas atividades: 1) delimitação da planície aluvial do rio Miranda com base em relações morfológicas reconhecidas em dados orbitais; 2) identificação dos diferentes estilos fluviais do canal; 3) mapeamento de geoformas deposicionais e erosivas, atuais e relictas; 4) reconhecimento de paleocanais e de evidências de mudanças no curso do rio.

\section{Resultados}

A planície aluvial do rio Miranda possui área aproximada de $4.165 \mathrm{~km}^{2}$. Desde suas nascentes até a altura da confluência com o rio Nioaque, o rio percorre cerca de $280 \mathrm{~km}$, como típico rio de leito rochoso, escavando rochas sedimentares da bacia do Paraná e formando um sistema tributário que coleta águas dos planaltos da Bodoquena e de Maracajú-Campo Grande.

$\mathrm{O}$ rio Miranda adquire características aluviais poucos quilômetros a jusante da confluência com o rio Nioaque (Figura 2). Ainda no domínio dos planaltos, o rio deixa de ser de leito rochoso e passa a correr numa planície agradacional, que está confinada num vale escavado em rochas metamórficas do Grupo Cuiabá, as quais formam o embasamento das rochas paleozoicas da bacia sedimentar do Paraná e do Pantanal.

Ao adentrar na planície do Pantanal, a cerca de 10 $\mathrm{km}$ a montante da confluência com o rio Salobra, o rio passa a correr numa planície morfologicamente heterogênea, que progressivamente se alarga, limitada ao sul e a leste por terrenos cristalinos aplanados da Depressão do Rio Paraguai, ao norte pelas planícies fluviais dos rios 
Aquidauana e Negro, e a oeste pelo cinturão de meandros atual do rio Paraguai.

O gradiente topográfico é muito baixo, resultado de cotas altimétricas que decrescem dos cerca de $140 \mathrm{~m}$, no início do domínio aluvial, para cerca de $83 \mathrm{~m}$ na confluência com o rio Paraguai. À exceção de curtíssimos trechos, o canal do rio Miranda apresenta índice de sinuosidade alto. Mesmo podendo ser classificado predominantemente como um rio do tipo meandrante, três segmentos fluviais distintos foram reconhecidos com base no estilo do canal, nos processos geomorfológicos atuantes, nas geoformas e paleogeoformas existentes, deposicionais e erosivas, e nas características da planície onde o rio corre. Estes três segmentos são condicionados por compartimentos geomorfológicos que se sucedem de montante para jusante: 1) cinturão de meandros em planície agradacional; 2) cordão de canal-diques em planície agradacional; 3) cinturão de meandros em planície degradacional (Figuras 3 e 4).

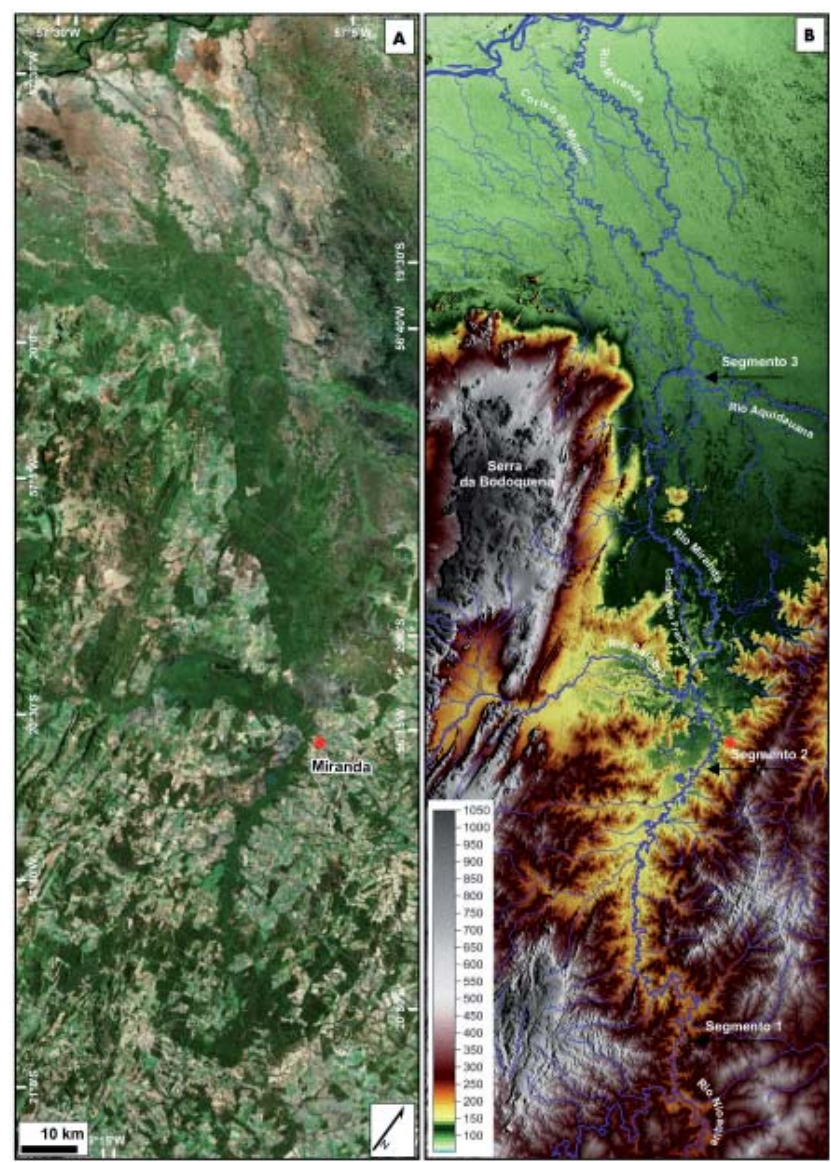

Figura 2 - Planície aluvial do rio Miranda. A) Imagem do plug in Bing Maps; B) MDE da área estudada, no qual os inícios dos segmentos identificados estão indicados por setas.

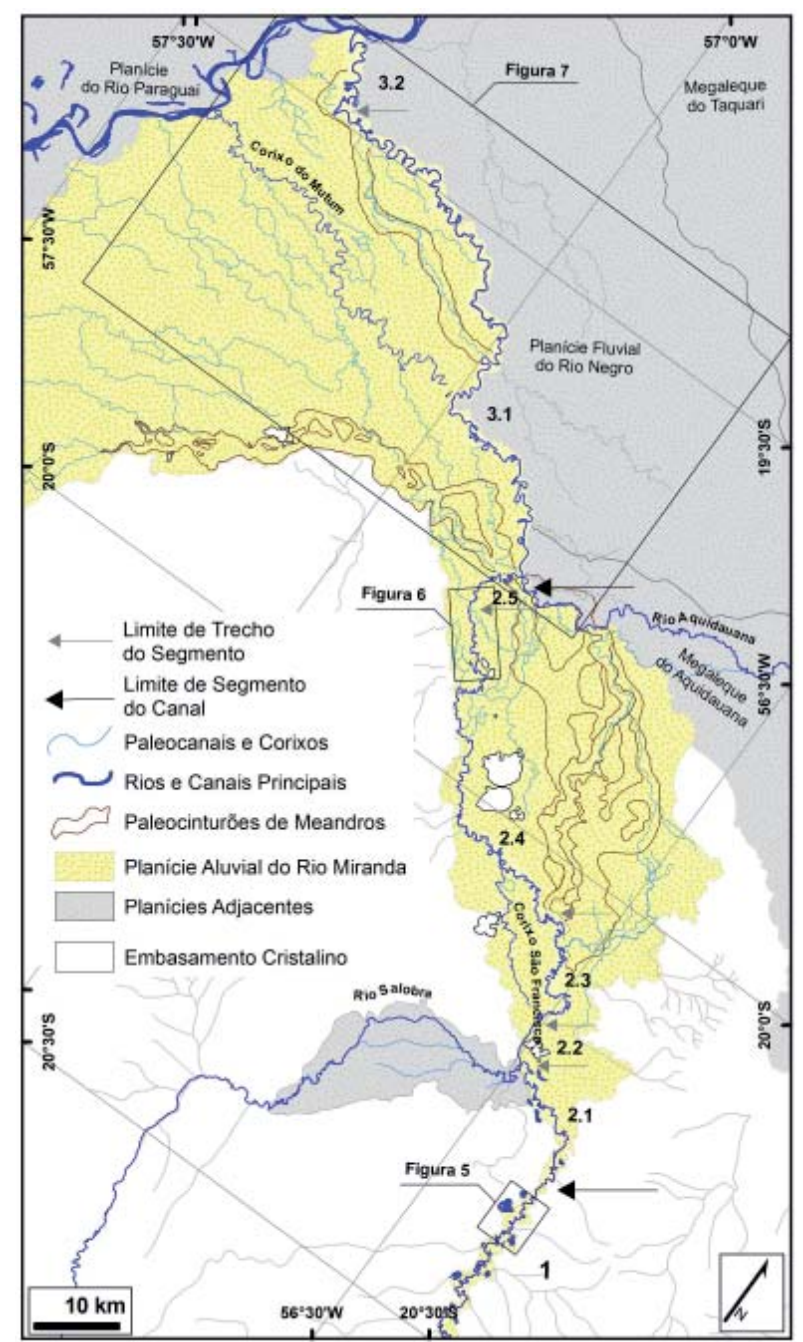

Figura 3 - Três segmentos aluviais do rio Miranda (Segmentos estão divididos em trechos: ver texto para explicação).

\section{Cinturão de meandros em planície agradacional}

A planície agradacional está confinada num vale escavado em rochas pré-cambrianas do Grupo Cuiabá. Neste segmento o canal do rio Miranda tem por volta de $150 \mathrm{~km}$ de extensão, largura média de $40 \mathrm{~m}$, gradiente topográfico médio de $0,17 \mathrm{~m} / \mathrm{km}$ e índice de sinuosidade de 2,29. A planície fluvial torna-se mais larga para jusante, progressivamente aumentando a dimensão e a quantidade das barras em pontal e de meandros abandonados. A estação fluviométrica Estrada MT-738, situada poucos quilômetros a montante do início do trecho aluvial, é a única do rio Miranda que registra dados de vazão em séries históricas de vários anos. Com base nestes dados, foram verificadas vazões médias mensais mínima de $34.9 \mathrm{~m}^{3} / \mathrm{s}$ e máxima de $237 \mathrm{~m}^{3} / \mathrm{s}$ no período 2002-2011. Os períodos com vazões menores ocorreram nos meses de agosto e setembro, enquanto que os de maior vazão nos meses de dezembro a março. 


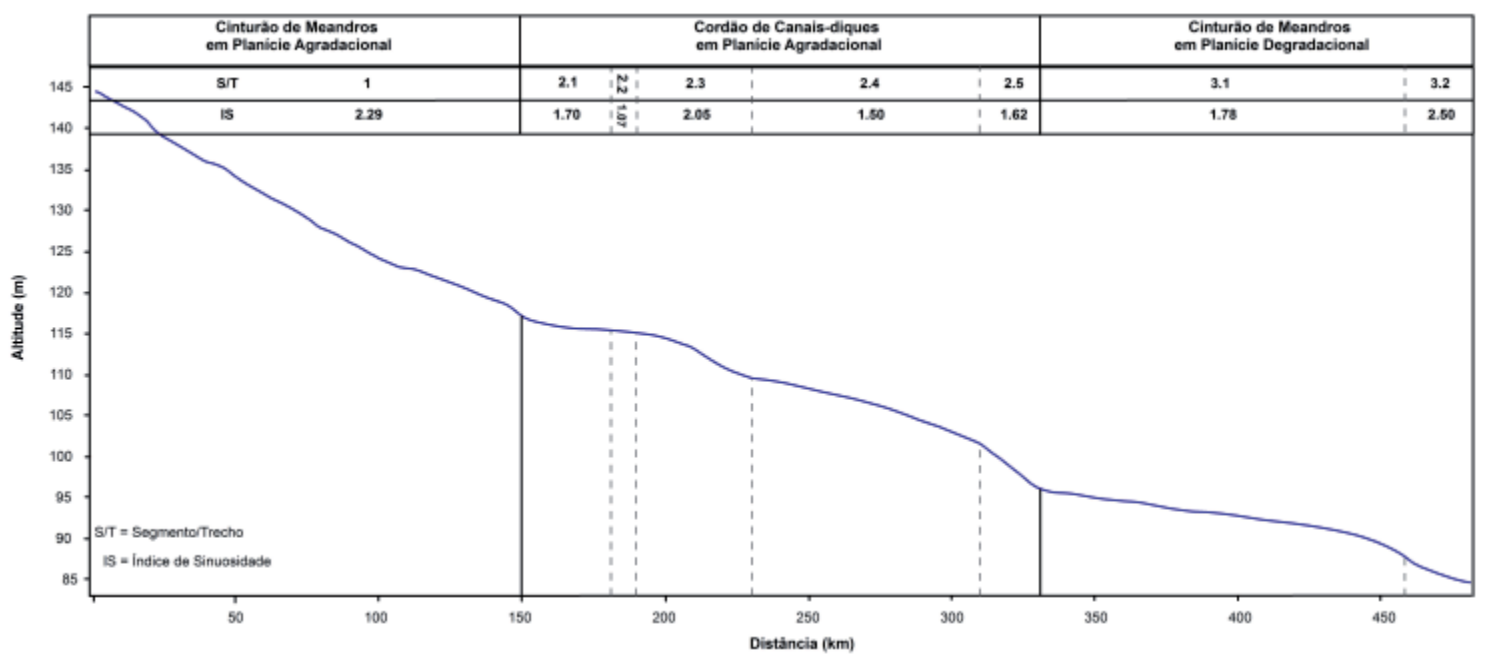

Figura 4 - Perfil longitudinal do rio Miranda em seu trecho aluvial.

Na metade inferior deste segmento, o cinturão atual superpõe feições relictas de canais meandrantes (Figura 5). Paleocanais com dimensões superiores às dos meandros atuais estão preservados na planície, assim como lagoas de meandro abandonado (oxbow lakes) com diferentes diâmetros e formas, algumas relativamente grandes $\left(1,7 \mathrm{~km}^{2}\right)$. Nessas áreas são formados grandes alagados onde predomina vegetação arbustiva, distinguindo-se da vegetação de grande porte predominante na planície atual do rio.
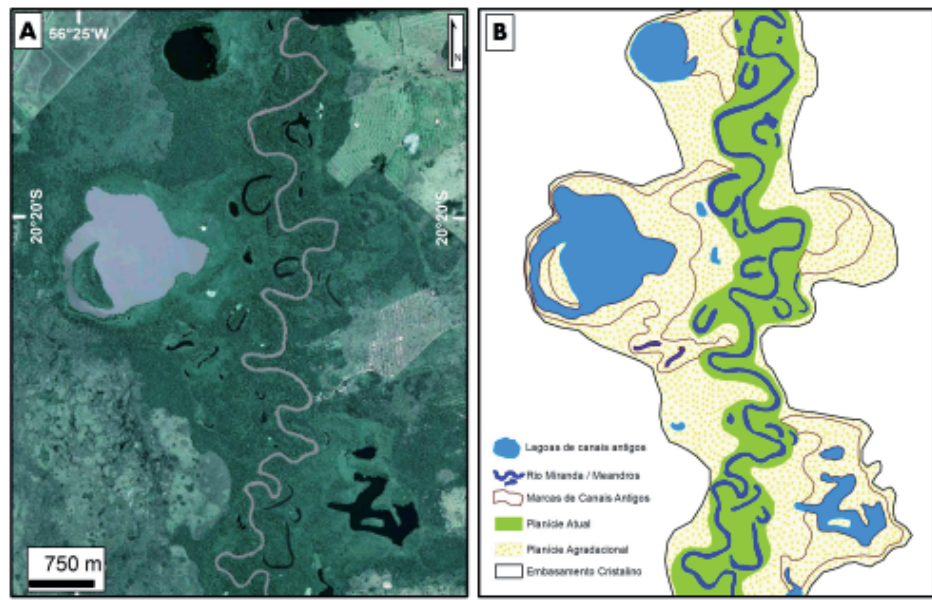

Figura 5 - Feições morfológicas do cinturão de meandros na planicie agradacional superior (Imagem Google Earth em A; localização da área na Figura 3).

\section{Cordão de canal-diques em planície agradacional}

$\mathrm{Na}$ altura da cidade de Miranda, o rio deixa de correr num cinturão de meandros e entra numa planície que progressivamente se alarga para norte, caracterizando sua entrada efetiva na planície do Pantanal na cota aproximada de $117 \mathrm{~m}$ (knick point). Neste segmento em que corre numa planície agradacional desconfinada, o rio tem extensão de 175 $\mathrm{km}$ e apresenta importantes mudanças nos seus valores de declividade e de sinuosidade, tendo sido possível distinguir cinco diferentes trechos (Figuras 3 e 4).

No primeiro trecho (2.1) deste segundo segmento, a declividade do canal diminui consideravelmente em relação àquela que tem estando confinado no cinturão de meandros, assim como a sinuosidade decresce de 2,29 para 1,70, o que ainda caracteriza o rio como de tipo meandrante. Por cerca de $20 \mathrm{~km}$ o rio flui com muito baixa declividade, até a confluência do rio Salobra, a partir de onde o canal adquire padrão retilíneo (trecho 2.2), correndo encaixado entre elevações residuais existentes na planície pantaneira e terrenos aplanados do embasamento cristalino.

Após percorrer este curto trecho retilíneo de $6 \mathrm{~km}$, o rio volta a ser meandrante, com índice de sinuosidade de 2,05 (2.3). Neste trecho de cerca de $40 \mathrm{~km}$ o canal atual está superimposto a um paleocinturão de meandros que apresenta paleocanais com dimensões semelhantes às dos paleocanais existentes na planície fluvial confinada.

O quarto trecho (2.4) se inicia no ponto onde o canal escapa do domínio do paleocinturão de meandros e deflete para oeste até a borda da planície, daí defletindo para noroeste e correndo neste rumo paralelamente ao contato com terrenos pré-cambrianos até o final do trecho. Neste trecho, o canal possui $80 \mathrm{~km}$ de extensão, gradiente uniforme de cerca de $0,04 \mathrm{~m} / \mathrm{km}$ e índice de sinuosidade de 1,5 , no limiar inferior do valor atribuído a rios meandrantes. No final do segmento há mudança no rumo do rio, que passa a fluir para nordeste, cortando transversalmente sua planície com declive mais acentuada e pequeno aumento da sinuosidade (de 1,50 para $1,62)$. 
O canal atual do rio apresenta-se na paisagem como forma deposicional composta por canal e diques marginais, que se destaca na planície de inundação por estarem em cotas topográficas mais altas, ressaltadas ainda mais em MDEs pela vegetação ripária desenvolvida sobre os diques marginais (Figura 6).

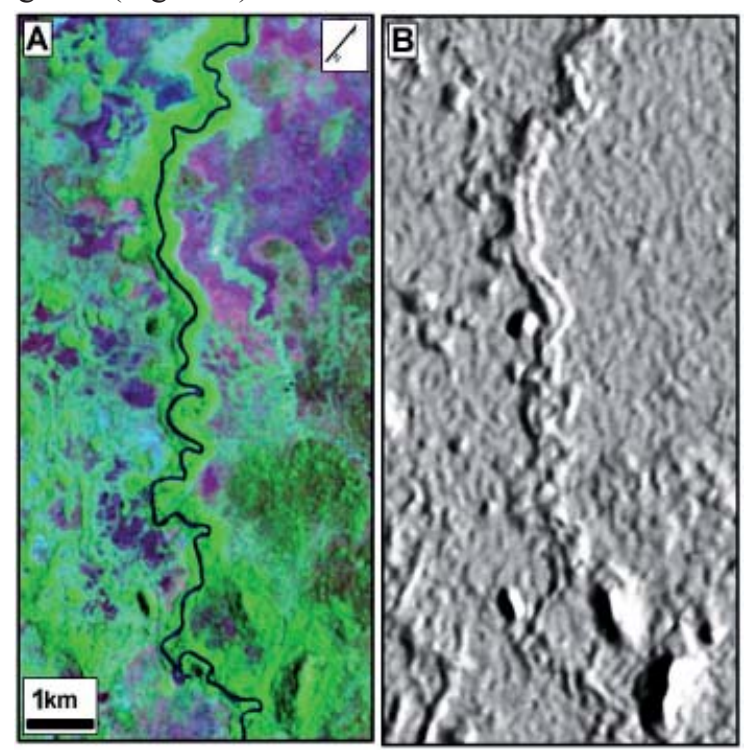

Figura 6 - Trecho do cordão de canal-diques em planície agradacional. A) Imagem GEOCOVER; B) MDE com relevo sombreado, no qual os diques marginais são acentuados pela vegetação ripariana (localização na Figura 3).

Pontos de rompimento (crevasse) dos diques marginais existem em todo o trecho, assim como na planície existem geoformas deposicionais de canal-diques construídas por antigos cursos do rio Miranda, testemunhando o caráter agradacional da planície neste segmento fluvial, onde há pouca migração lateral do rio e as mudanças ocorrem por avulsão fluvial. O corixo São Domingos, localizado na margem esquerda do canal atual, é produto de avulsão sofrida pelo rio Miranda na parte final do trecho retilíneo (Figura 3).

\section{Cinturão de meandros em planície degradacional}

Da confluência com o rio Aquidauana até a sua foz no rio Paraguai, o rio Miranda percorre segmento de $156 \mathrm{~km}$ num cinturão de meandros na margem direita da planície aluvial do sistema deposicional do rio Miranda (Figura 7). O gradiente topográfico do rio é de $0,079 \mathrm{~m} / \mathrm{km}$ e o índice de sinuosidade do canal de 1,78. Após a confluência com o rio Aquidauna, a vazão aumenta consideravelmente, de 33 $\mathrm{m}^{3} / \mathrm{s}$ para $123 \mathrm{~m}^{3} / \mathrm{s}$ em medições realizadas com equipamento ADCP no mês de setembro de 2012, assim como a largura, que passa de menos de $50 \mathrm{~m}$ antes da confluência para mais de $100 \mathrm{~m}$ depois dela.

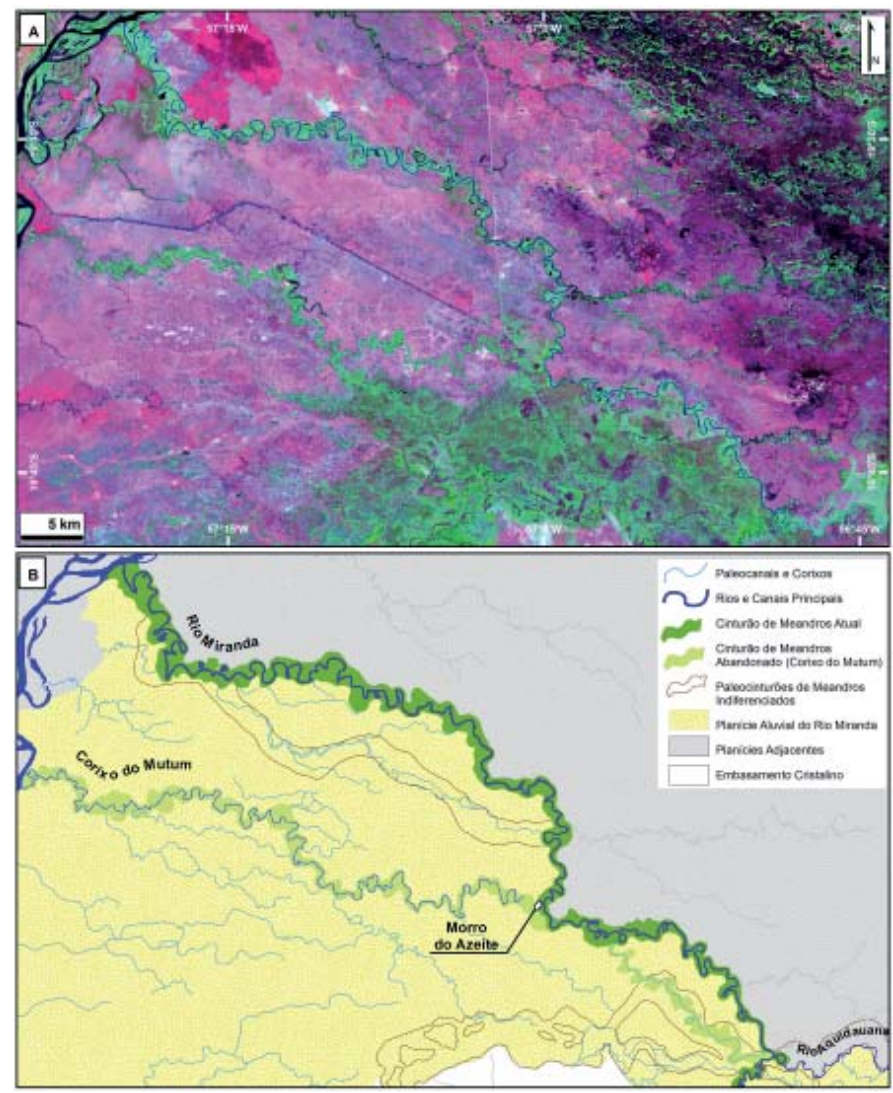

Figura 7-O cinturão de meandros atual do rio Miranda encontrase inciso em depósitos aluviais antigos da planície degradacional, na qual se destacam também o cinturão abandonado onde está o corixo do Mutum (Imagem Landsat 7 ETM+R7G4B2; localização na Figura 3).

O cinturão de meandros atual está inciso em depósitos aluviais mais antigos e sua largura diminui de jusante para montante, delineando ponto de entalhe (knickpoint) nas proximidades do início do segmento, ou seja, da confluência com o rio Aquidauana. Assim como a largura é maior, também se observa aumento na amplitude dos meandros e no desenvolvimento de barras em pontal para jusante. Esta configuração é evidência de que o cinturão evoluiu por erosão lateral, com rebaixamento do canal controlado pelo rio Paraguai, que é o nível de base do rio Miranda.

Na planície degradacional estão impressas marcas de paleocanais que, apesar de bastante obliteradas, remetem a épocas que o rio Miranda apresentava padrão de drenagem diferente do atual, com bifurcações e confluências delineando padrão distributário/multicanal (anabranching). Em parte, os paleocanais foram reocupados por pequenos cursos d'água, localmente denominados "corixos", os quais formam incipiente rede de drenagem tributária que erodem e retrabalham os sedimentos superficiais e contribuem para drenar as águas de inundação. 
O corixo do Mutum inicia-se nas proximidades do morro do Azeite, uma elevação onde afloram rochas do embasamento cristalino e que quebra a monotonia da topografia quase plana da planície. O corixo está instalado num cinturão de meandros abandonado, semelhante ao do atual rio Miranda, com canais abandonados de dimensões similares às do atual Miranda.

A planície degradacional do baixo curso do rio Miranda apresenta grande interação com o megaleque do rio Aquidauana e com a planície do rio Negro, sendo coletor das águas de ambos os sistemas. Durante as cheias, a planície é palco de fluxo em lençol de águas provenientes das planícies dos rios Negro e Aquidauana, que retralham a superfície da planície e obliteram feições morfológicas antigas.

\section{Discussão dos resultados}

A bacia hidrográfica do Alto Rio Paraguai é caracterizada pela presença de rios que apresentam diferentes estilos fluviais. A grande extensão da bacia é um dos fatores que condicionam a existência de rios com diferentes regimes hidrológicos no Pantanal, o que é também registrado em grandes bacias hidrográficas de regiões tropicais (LATRUBESSE et al., 2005).

O rio Miranda apresenta sinuosidade média a alta no seu domínio aluvial, sendo do tipo meandrante na maior parte do percurso. A natureza agradacional do cinturão de meandros do primeiro segmento fluvial, que está confinado em vale escavado em rochas do embasamento cristalino, tem gênese intimamente relacionada à sedimentação no segundo segmento, que se inicia na entrada do Pantanal. A sedimentação neste segundo domínio agradacional favoreceu elevação do nível de base com geração de espaço de acomodação a montante.

Na maior parte do segundo segmento fluvial, o rio forma um cordão composto pelo canal e seus diques marginais, correndo em posição altimétrica mais elevada numa planície de inundação que se alarga para jusante. $\mathrm{O}$ rio apresenta pouca migração lateral e reduzido número de meandros abandonados, sendo as mudanças de curso desencadeadas por avulsão. Como resultado de mudanças de curso, formas deposicionais de cordões abandonados ocorrem na planície, sendo exemplo o corixo São Francisco (Figura 3).

Importante destacar que o rio no segundo compartimento agradacional corre na margem oeste da planície, o que sugere basculamento da planície para oeste e controle por estruturas de direção NW.

Depósitos sedimentares quaternários são excelentes arquivos que registram mudanças ambientais, permitindo acesso ao passado recente (BRIDGE, 2003; PERRY e TAYLOR, 2007). A existência destas feições deposicionais relictas é testemunho de mudanças ambientais ocorridas na bacia do Pantanal desde o Pleistoceno tardio (ASSINE e SOARES, 2004; McGLUE et al. 2012; KUERTEN et al., 2013).
Paleocinturões de meandros existentes nos dois compartimentos agradacionais, em parte sobrepostos pelo canal atual (Figura 4), são registros de paleossistemas hidrológicos que, pelas dimensões dos seus meandros, tinham descarga fluvial superior à do atual. Não existem, entretanto, informações sobre idades dos depósitos destes cinturões, cuja formação ocorreu em algum período de aumento da precipitação, possivelmente durante o Holoceno Médio, quando teria havido predominância de climas mais úmidos que o atual na região do Pantanal (McGLUE et al., 2012).

Os cinturões de meandros mapeados na planície degradacional são evidências de importante avulsão no rio Miranda nas proximidades do Morro do Azeite (Figura 7). Com a avulsão houve reorganização na drenagem atual do rio Miranda, que passou a fluir para noroeste dentro do cinturão de meandros atual, desaguando no rio Paraguai cerca de 20 $\mathrm{km}$ da sua antiga foz.

O cinturão de meandros abandonado foi ocupado pelo Corixo do Mutum, um rio intermitente, subajustado no cinturão abandonado e que funciona como canal de drenagem da planície depois do período de cheias, quando toda a área é palco de fluxos em lençol de águas que transbordam dos leitos dos rios Miranda, Aquidauana e Negro.

A área degradacional apresenta formas deposicionais mais antigas, bastante obliteradas pela ação das águas das cheias anuais. Antigos cinturões de meandros e redes de paleocanais distributários/anabranching remetem a épocas anteriores, quando o rio Miranda apresentava planície distal também agradacional.

\section{Conclusões}

O rio Miranda apresenta características que o diferem de outros rios do Pantanal, pois não forma um megaleque tal como acontece nos rios Taquari, São Lourenço e Aquidauana. $\mathrm{O}$ rio tem sinuosidade média a alta no seu domínio aluvial, o que o caracteriza como rio do tipo meandrante na maior parte do seu percurso.

Com base nos padrões do canal e elementos morfológicos da planície, o rio foi compartimentado em três segmentos fluviais geomorfologicamente distintos. No início do domínio aluvial o rio forma um cinturão de meandros numa planície agradacional, que está confinada em vale escavado no embasamento cristalino situado a montante da entrada do rio no Pantanal. Ao adentrar no Pantanal, o rio deixa de correr num cinturão de meandros para formar um cordão composto por canal e diques marginais, que se destaca pela elevação mais alta em relação à planície agradacional que progressivamente se alarga para jusante. No segmento inferior, o rio volta a correr num cinturão de meandros, todavia diferente do superior, uma vez que está inciso em depósitos aluviais da planície distal, onde predominam processos degradacio- 
nais, tanto pela ação de águas de rede de pequenos canais tributários superimpostos, quanto pelas águas de fluxos em lençol durante as cheias.

Característica peculiar da planície aluvial do rio Miranda é que seu compartimento agradacional está localizado na parte medial do sistema, e não na distal como normalmente ocorre nos sistemas aluviais. Tanto subsidência diferencial, devido a movimentos neotectônicos, quanto barramento pelos cordões dos rios Miranda e Aquidauana podem ter atuado concomitantemente para a geração de espaço de acomodação na planície, que por isto permanece frequentemente inundada.

Paleocinturões de meandros e grandes meandros abandonados com dimensões superiores às dos canais atuais remetem a mudanças ambientais e paleohidrológicas ocorridas a partir do final do Pleistoceno.

Avulsões recentes desempenharam importante papel na configuração do traçado atual do canal do rio Miranda. A avulsão ocorrida na altura do Morro do Azeite causou deslocamento em $20 \mathrm{~km}$ para norte de sua foz no rio Paraguai. Ao mesmo tempo, o cinturão de meandros abandonado foi ocupado pelo corixo do Mutum, um rio intermitente e subjustado dentro do cinturão, que atua como canal de drenagem das águas que inundam a planície durante as cheias.

\section{Agradecimentos}

Os autores agradecem à Fundação de Amparo a Pesquisa do Estado de São Paulo pelo fomento a pesquisas no Pantanal (FAPESP 2007/55987-3), ao CNPq pelo apoio financeiro (305108/2009-3) e à CAPES pela concessão de bolsa de mestrado ao primeiro autor.

\section{Referências bibliográficas}

ASSINE, M. L. River avulsions on the Taquari megafan, Pantanal wetland, Brazil. Geomorphology, v. 70, n. 3-4, p. 357-371, 2005.

ASSINE, M. L.; SILVA, A. Contrasting fluvial styles of the Paraguay River in the northwestern border of the Pantanal wetland, Brazil. Geomorphology, v. 113, n. 3-4, p. 189-199, 2009.

ASSINE, M. L.; SOARES, P. C. Quaternary of the Pantanal, west-central Brazil.Quaternary International, v. 114, n. 1, p. 23-34, 2004.

BRIDGE, J. S. Rivers and floodplains: forms, processes, and sedimentary record. Oxford: Wiley-Blackwell, 2003. 491 ISBN 978-0632064892.

CORRADINI, F. A.; ASSINE, M. L. Compartimentação geomorfológica e processos deposicionais no megaleque fluvial do Rio São Lourenço, Pantanal Mato-Grossense. Revista Brasileira de Geociências, v. 42, p. 20-33, 2012.
HAMILTON, S. K.; SIPPEL, S. J.; MELACK, J. Inundation patterns in the Pantanal wetland of South America determined from passive microwave remote sensing. Archiv Fur Hydrobiologie, v. 137, n. 1, p. 1-23, 1996.

JUNK, W. J. et al. Biodiversity and its conservation in the Pantanal of Mato Grosso, Brazil. Aquatic Sciences, v. 68, p. 278-309, 2006.

JUNK, J. W.; BAYLEY, P. B.; SPARKS, R. E. The flood pulse concept in river floodplain systems. Canadian Special Publications of Fisheries and Aquatic Sciences, v. 106, p. 110-127, 1989.

http://ppg.sagepub.com/cgi/content/abstract/26/3/400 >.

KUERTEN, S.; ASSINE, M. L. O rio Paraguai no megaleque do Nabileque, sudoeste do Pantanal Mato-Grossense, MS. Revista Brasileira de Geociências, v. 41, n. 4, p. 655-666, 2011.

KUERTEN, S.; PAROLIN, M.; ASSINE, M. L.; MCGLUE, M. Sponge spicules indicate Holocene environmental changes on the Nabileque River floodplain, southern Pantanal, Brazil. Journal of Paleolimnology, v. 49, n. 2, p. 171-183. 2013.

LATRUBESSE, E. M.; STEVAUX, J. C.; SINHA, R. Grandes sistemas fluviais tropicais: uma visão geral. Revista Brasileira de Geomorfologia, v. 6, n.1, p. 1-18, 2005.

McGLUE, M. M; SILVA A.; ZANI H.; CORRADINI F. A.; PAROLIN, M.; ABEL, E. J.; COHEN, A. S., ASSINE, M. L.; TREES, M. A.; KUERTEN, S.; GRADELLA, F. S.; RASBOLD, G. G. Lacustrine records of Holocene flood pulse dynamics in the Upper Paraguay River watershed (Pantanal wetlands, Brazil). Quaternary Research, v. 78, p. 285-294, 2012.

PADOVANI, C. R. Dinâmica das Inundações do Pantanal. 2010. 174 (Doutorado). Ecologia Aplicada, Universidade de São Paulo/ESALQ, Piracicaba - SP. PERRY, C. T.; K., T. Environmental Sedimentology. WileyBlackwell, 2006. 452 ISBN 978-1-4051-1515-5.

SILVA, J. S. V.; ABDON, M. M. Delimitação do Pantanal brasileiro e suas sub-regiões. Pesquisa Agropecuária Brasileira. Brasília. 33 (Especial): 1703-1711 p. 1998.

SOARES, A. P.; SOARES, P. C.; ASSINE, M. L. Areiais e lagoas do Pantanal, Brasil: herança paleoclimática? Revista Brasileira de Geociências, v. 33, p. 211-224, 2003.

STOTT, T. Fluvial geomorphology 2008-2009. Progress in Physical Geography, v. 35, n. 6, p. 810-830, 2011.

TRICART, J. El Pantanal: un ejemplo del impacto geomorfologico sobre El ambiente. Informaciones Geograficas (Chile), v. 29, p. 81-97, 1982.

ZANI, H.; ASSINE, M. L.; MCGLUE, M. M. Remote sensing analysis of depositional landforms in alluvial settings: Method development and application to the Taquari megafan, Pantanal (Brazil). Geomorphology, v. 161-162, p. 82-92, 2012. 